\title{
PERANCANGAN SISTEM INFORMASI PENDATAAN PELATIHAN P2M DEPARTEMEN TEKNIK MESIN UNIVERSITAS INDONESIA
}

\author{
Sulthan Aprilian' ${ }^{1}$ Fitriana Destiawati², Indra Kurniawan ${ }^{3}$ \\ ${ }^{1,2,3}$ Universitas Indraprasta PGRI \\ Jalan Raya Tengah No 80, Kelurahan Gedong, Pasar Rebo, Jakarta Timur

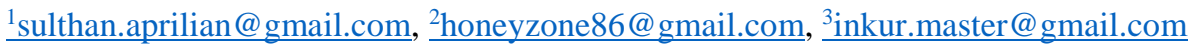

\begin{abstract}
ABSTRAK
P2M Departemen Teknik Mesin Universitas Indonesia merupakan perusahaan / wadah interaksi pada bidang pendidikan atau masyarakat yang telah berdiri pada tahun 1985. Tujuan penelitian adalah untuk meningkatkan pelayanan kepada calon peserta pelatihan dalam melakukan proses pendaftaran hingga proses pembayaran pada P2M Departemen Teknik Mesin Universitas Indonesia, mempermudah dan membantu pihak departemen dalam proses laporan yang sedang berjalan, dan membuat aplikasi agar lebih efisien dari sistem sebelumnya pada P2M Departemen Teknik Mesin Universitas Indonesia. Metode penelitian yang digunakan oleh peneliti dalam perancangan ini adalah metode penelitian kualitatif dengan desain waterfall yaitu metode yang mengintikan fase-fase yang berurutan dan sistematis, dimulai dari spesifikasi kebutuhan konsumen dan berkembang melalui proses perencanaan, pemodelan, pembangunan, dan penyebaran, yang berujung pada dukungan terus menerus untuk sebuah perangkat lunak yang utuh. Selama melakukan penelitian, penulis menemukan bahwa pada P2M Departemen Teknik Mesin Universitas Indonesia masih belum memiliki sistem informasi pengolahan data yang teraplikasi dengan baik. Setelah melakukan penelitian, penulis memberikan kesimpulan bahwa P2M Departemen Teknik Mesin Universitas Indonesia membutuhkan sistem informasi yang teraplikasi sehingga dapat membantu karyawan dalam melaksanakan pekerjaannya. Dari hasil penelitian tersebut sehingga peneliti memutuskan untuk membuat Sistem Informasi Pendataan Pelatihan Pada P2M Departemen Teknik Mesin Universitas Indonesia.
\end{abstract}

Kata Kunci: Sistem, Informasi, Pendataan, Pelatihan, Java

\begin{abstract}
P2M Department of Mechanical Engineering, University of Indonesia is a company / forum for interaction in the field of education or society that was established in 1985. The purpose of the research is to improve services to prospective trainees in the registration process to the payment process at P2M Department of Mechanical Engineering, University of Indonesia, simplifying and assist the department in the ongoing report process, and make applications to be more efficient than the previous system at the P2M Department of Mechanical Engineering, University of Indonesia. The research method used by researchers in this design is a qualitative research method with a waterfall design, which is a method that initiates sequential and systematic phases, starting from the specification of consumer needs and progressing through the process of planning, modeling, development, and deployment, which leads to support continuously for a complete software. During the research, the authors found that the P2M Department of Mechanical Engineering, University of Indonesia still does not have a well-applied data processing information system. After conducting research, the author concludes that P2M Department of Mechanical Engineering, University of Indonesia requires an applied information system so that it can assist employees in carry out their work. From the results of these studies, the researchers decided to create a Training Data Collection Information System at the P2M Department of Mechanical Engineering, University of Indonesia.
\end{abstract}

Key Word: System, Information, Datacollection, Training, Java

\section{PENDAHULUAN}

Perkembangan yang terjadi di bidang Teknologi saat ini begitu pesat dan sangat berpengaruh terhadap suatu perusahaan, pribadi maupun komunitas yang terbentuk. P2M Departemen Teknik Mesin Universitas Indonesia merupakan perusahaan / wadah interaksi pada bidang pendidikan atau masyarakat yang telah berdiri pada tahun 1985. Namun, sistem yang digunakan pada
P2M Departemen Teknik Mesin Universitas Indonesia masih konvensional dalam melakukan registrasi pelatihan, selain ini departemen tersebut belum memaksimalkan sistem tersebut untuk para calon pelatihan melakukan pendaftaran pelatihan. Oleh sebab itu, penulis membuat sistem yang terkomputerisasi diharapkan dapat mengatasi masalah-masalah yang timbul dalam sistem yang pekerjaannya banyak dilakukan secara 
konvensional sehingga dapat meningkatkan efesiensi dan kemajuan pada P2M Departemen Teknik Mesin Universitas Indonesia. Namun, ada beberapa kendala yang dihadapi pada Rental Mobil Akbar Depok yaitu proses pendaftaran customer untuk melakukan rental masih secara konvensional yaitu dicatat ke dalam kertas atau buku, sehingga memakan banyak waktu untuk memproses ke tahap selanjutnya penyimpanan data yang dilakukan tidak menggunakan database laporan setiap bulan masih dibuat secara konvensional dengan menggunakan media kertas. Manfaat dilakukannya penelitian ini adalah agar menjadi bahan evaluasi bagi Departemen untuk mengembangkan lebih maksimal lagi dalam kegunaannya serta sebagai bahan identifikasi kelemahan peluang pada P2M Departemen Teknik Mesin Universitas Indonesia.

Menurut (Subhan, 2012), "Perancangan merupakan teknik pengembangan spesifikasi baru sesuai rekomendasi hasil analisis sistem".

Menurut (Sutabri, 2012), "Sistem merupakan rangkaian unsur yang hubungannya erat satu dengan yang lain dan berfungsi untuk mencapai tujuan tertentu secara bersamaan". Menurut Zakiyudin dalam (Bobby, 2020) mendefinisikan, "Informasi merupakan data yang telah berjalan sedemikian rupa yang berguna untuk mengembangkan pengetahuan seseorang yang memerlukan data tersebut".

Menurut Sutarman dalam (Ahmad, 2018), "Sistem informasi merupakan teknik yang didapat dengan cara menggabungkan, memproses, mengemasi, menganalisa, dan menyebarkan informasi yang memiliki tujuan tertentu.".

Menurut (Pauziah, 2013), "Pendataan diartikan sebagai teknik pembuktian dari hasil penelitian dan lebih dikaitkan dengan pengumpulan secara empiris".

Menurut (Yulianti, 2015), "Pelatihan mempunyai pengertian proses pengembangan diri kepada karyawan agar bisa bekerja lebih terampil dan meningkatkan pengetahuan maupun keahlian karyawan.”.

\section{METODE PENELITIAN}

Metode penelitian yang digunakan oleh peneliti adalah metode kualitatif. Menurut (Darna \& Herlina, 2018), Metode penelitian kualitatif merupakan metode yang berdasarkan pada filsafat postpositivisme berguna untuk meneliti pada kondisi objek yang alamiah, (sebagai lawannya adalah eksperimen) dimana peneliti adalah sebagai instrumental kunci, pengambilan sampel sumber data dilakukan secara purposive dan snowbaal, teknik pengumpulan dengan trianggulasi (gabungan), analisis data bersifat induktif/kualitatif, dan hasil penelitian kualitatif lebih tertuju pada makna daripada generalisasi.

Menurut Riduwan yang dikutip (Tanujaya, 2017), Metode pengumpulan data merupakan teknik yang diperlukan oleh peneliti untuk mengumpulkan data-data. Metode pengumpulan data yang digunakan, antara lain:

\section{Observasi}

Peneliti melakukan kunjungan untuk melakukan penelitian pada P2M Departemen Teknik Mesin Universitas Indonesia bulan Maret 2021 yang lalu. Penulis mendapatkan data peserta pelatihan, data materi pelatihan, data jadwal pelatihan, data jadwal kegiatan, data pembayaran, dan pengumpulan datadata terhadap proses kerja sistem yang berjalan pada P2M Departemen Teknik Mesin Universitas Indonesia.

2. Studi Kepustakaan

Peneliti melakukan penelitian dengan berdasarkan karya tulis, baik yang telah atau belum dipublikasi.

3. Wawancara

Penulis melakukan pengumpulan data dengan melakukan tanya jawab dan tinjauan dengan karyawan yang bertugas menangani data pada P2M Departemen Teknik Mesin Universitas Indonesia.

Metode pengembangan sistem yang digunakan oleh peneliti adalah metode Waterfall. Menurut (Pressman, 2015), Waterfall adalah "Waterfall merupakan Model klasik yang sistematis, berurutan dalam membangun sebuah software. Nama lain dari model ini adalah "Linear Sequential Model" dan sering disebut juga dengan "Classic Life Cycle" atau "metode Waterfall". 


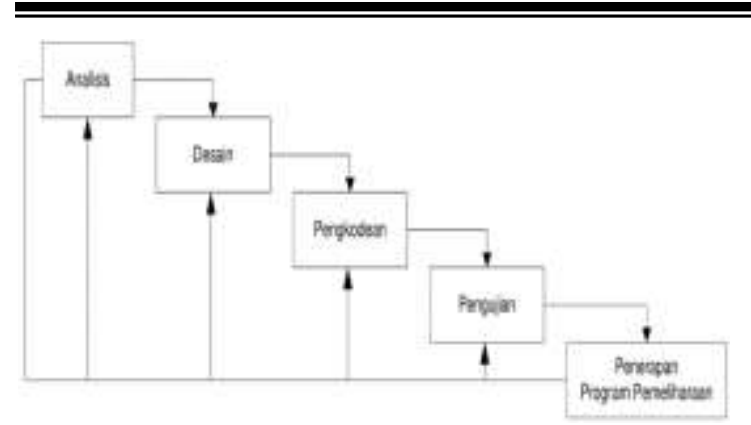

Gambar 1. Metode Waterfall

Metode penelitian menjelaskan desain penelitian, rancangan kegiatan, ruang lingkup, objek penelitian, tempat penelitian, teknik pengumpulan data, dan teknik analisis penelitian.

\section{HASIL DAN PEMBAHASAN}

Tahapan Metode Waterfall sebagai berikut:

1. Analisa kebutuhan sistem, dilakukan pengumpulan dengan berfokus pada perangkat lunak, meliputi informasi, fungsi masing-masing pada sistem, kerja/cara antar muka. Sebelum merancang sebuah sistem, penulis harus memahami kebutuhan P2M Departemen Teknik Mesin Universitas Indonesia tersebut, apa saja yang diinginkan untuk mempermudah pekerjaannya.

2. Desain sistem, merupakan penyaluran pikiran dan perancangan sistem terhadap solusi dari permasalahan yang ada pada P2M Departemen Teknik Mesin Universitas Indonesia dengan menggunakan perangkat permodelan diagram alir data, hubungan entitas serta struktur data dan bahasanya.

3. Penulisan Kode Program, Pada Tahap ini dibuat pengkodean membangun aplikasi P2M Departemen Teknik Mesin Universitas Indonesia yang merupakan tahap untuk membuat suatu kode tentang aplikasi yang dibuat agar dapat dibaca serta telah diterjemahkan oleh bahasa komputer.

4. Pengujian Program, Pengujian ini bertujuan untuk mengantisipasi masalahmasalah antarmuka serta perancangan jalur penanganan kesalahan yang terjadi antar sistem pada perangkat lunak.

5. Penerapan Program dan Pemeliharaan, Pada tahap ini dilakukan tahap yaitu mengoreksi kesalahan yang terjadi pada perangkat lunak yang dapat diketahui saat perangkat lunak digunakan. Dengan adanya tahap pengoreksi kesalahan terhadap aplikasi sistem pengarsipan maka kesalahan-kesalahan yang terdapat pada informasi penjualan ini dapat di perbaiki.

\section{Analisa Permasalahan}

Setelah melakukan penelitian maka analisis permasalahan sebagai berikut:

1. Proses pendataan pelatihan pada P2M Departemen Teknik Mesin Universitas Indonesia masih menggunakan sistem konvensional.

2. Adanya kesulitan dalam melakukan pencarian dokumen arsip, dikarenakan sistem masih menggunakan konvensional yang mengakibatkan memakan waktu yang lama.

3. laporan pengolahan data setiap bulan masih dibuat dengan menggunakan Ms. Word serta Ms. Excel.

\section{Alternatif Penyelesaian Masalah}

Setelah peneliti menganalisa permasalahan lalu peneliti membuat alternatif penyelesaian masalah sebagai berikut:

1. Membuat sistem informasi pengolahan data pelatihan pada P2M Departemen Teknik Mesin Universitas Indonesia yang sudah teraplikasi sehingga memudahkan dalam melakukan pendataan.

2. Membuat database yang sistematis yang berguna untuk memudahkan dalam pencarian data yang dibutuhkan dalam pembuatan laporan.

3. Membuat aplikasi dengan memaksimalkan untuk mengurangi kesalahan atau kehilangan data.

\section{Aturan Bisnis Sistem yang Diusulkan}

1. Proses Pendaftaran Peserta: peserta memberikan identitas kepada karyawan yang akan diinput oleh karyawan ke dalam Data Peserta.

2. Proses Pendataan Materi: peserta akan memilih materi yang akan diambil saat pelatihan kepada karyawan yang akan dimasukan karyawan ke dalam Data Materi.

3. Proses Pendataan Pelatihan: Karyawan memasukan identitas pelatih yang akan memandu pelatihan ke dalam Data Pelatih.

4. Proses Jadwal Pelatihan: Karyawan akan menginput jadwal pelatihan sesuai dengan materi yang diambil oleh peserta yang akan diberikan pada peserta. 
5. Proses Transaksi: Peserta membayar sesuai dengan materi yang diambil lalu karyawan akan menginput data tersebut ke dalam Data Pembayaran

6. Proses Cetak Laporan: Karyawan mencetak laporan sesuai dengan Data yang akan diberikan kepada Direktur.

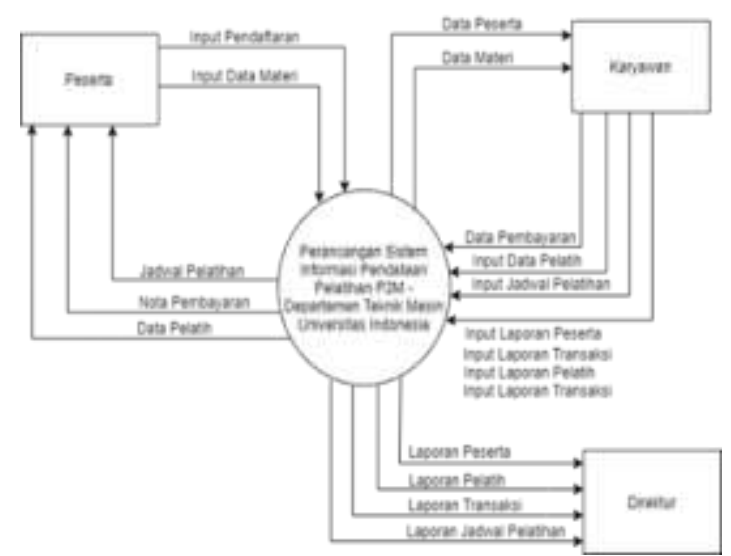

Gambar 2. Diagram konteks

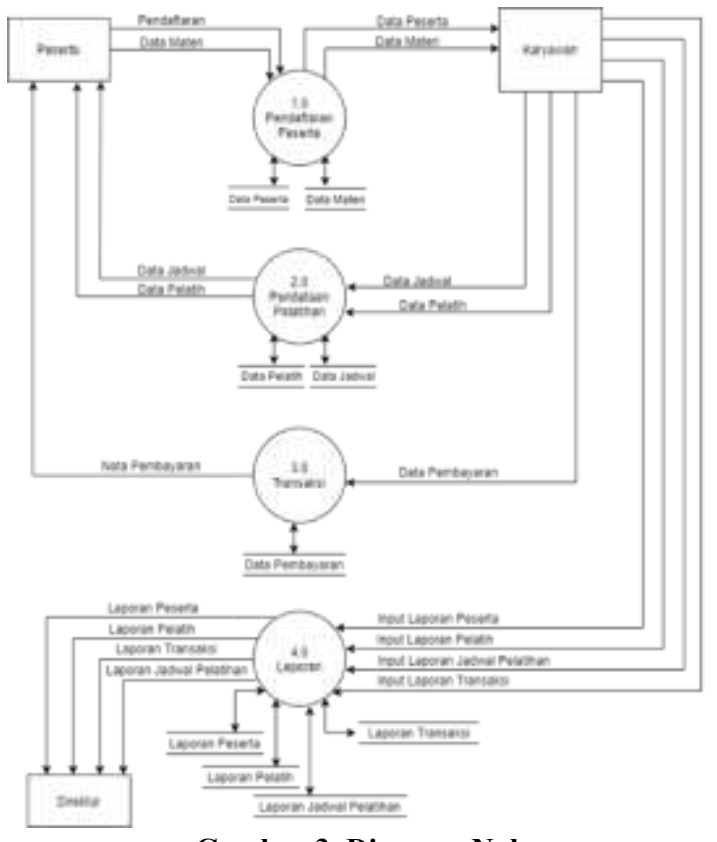

Gambar 3. Diagram Nol
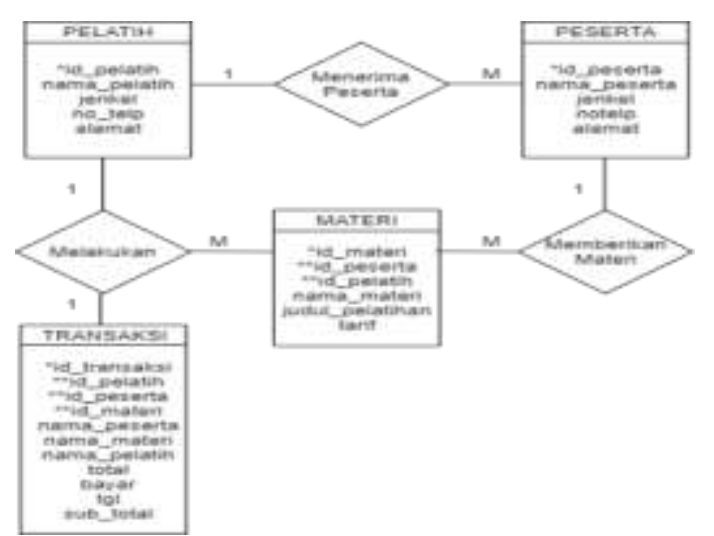

Gambar 4. Entity Relationship Diagram
Tampilan Layar

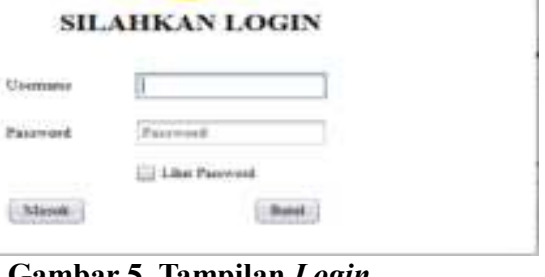

Gambar 5. Tampilan Login

Pada tampilan diatas merupakan rancangan tampilan Menu Login. Menu Login terdiri dari Username dan Password serta pilihan hak akses sebagai akses saat kita menjalankan program utama supaya tidak ada orang yang dapat mengakses program ini dengan sembarangan. Apabila pengguna telah memasukkan data login dengan tepat, maka menu utama akan tampil dan program siap untuk dijalankan.

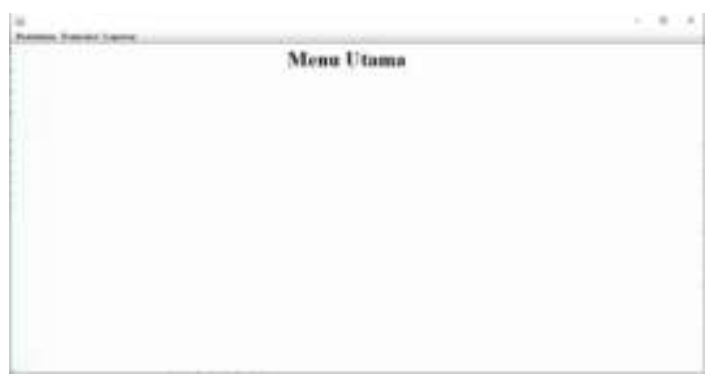

Gambar 6. Tampilan Menu Utama

Tampilan diatas merupakan Menu Utama yang terdiri dari Menu Pendaftaran, Menu Transaksi, dan Menu Laporan. Menu Pendaftaran terdapat Menu Pelatih, Menu Peserta, dan Menu Materi. Menu Transaksi terdapat Menu Pembayaran dan Menu Data Pembayaran. Menu Laporan terdapat Menu Laporan Pelatih, Menu Laporan Peserta, Menu Pelatihan, dan Menu Transaksi

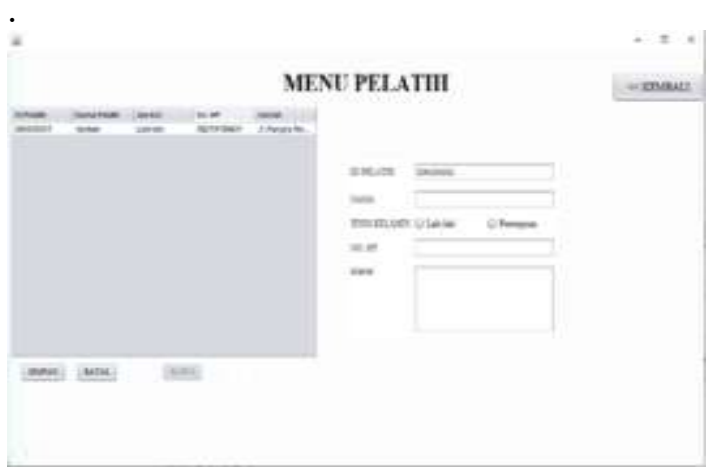

Gambar 7. Tampilan Menu Pelatih

979 | Perancangan Sistem Informasi Pendataan Pelatihan P2M Departemen Teknik Mesin Universitas Indonesia 
Tampilan Menu Pelatih berikut ini berfungsi untuk mendata pelatih yang akan mengikuti proses pelatihan yang akan berlangsung nantinya. Terdapat juga tombol simpan, batal, dan hapus.

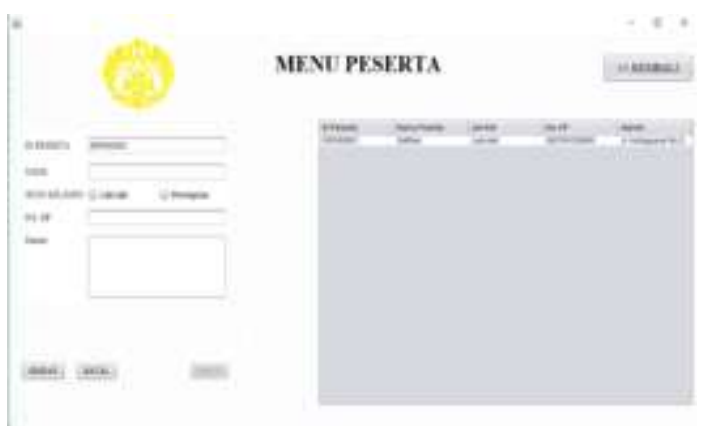

Gambar 8. Tampilan Menu Peserta

Tampilan Menu Peserta berikut ini berfungsi untuk mendata peserta yang akan mengikuti pelatihan. Terdapat juga tombol simpan, batal, dan hapus.

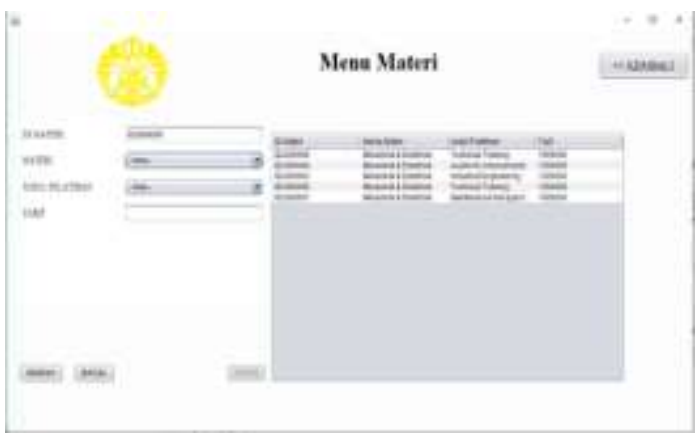

Gambar 9. Tampilan Menu Materi

Tampilan Menu Transaksi berikut ini berfungsi mendata Id Pelatih, Nama Pelatih, Id Peserta, Nama Peserta, Id Materi, Nama Materi, Judul Pelatihan, Tarif, Jumlah Harga Pelatihan, Subtotal harga pelatihan, dan Tanggal Pelatihan yang akan di proses oleh karyawan. Setelah itu akan keluar Output Kwintansi dan Output Cetak Jadwal.

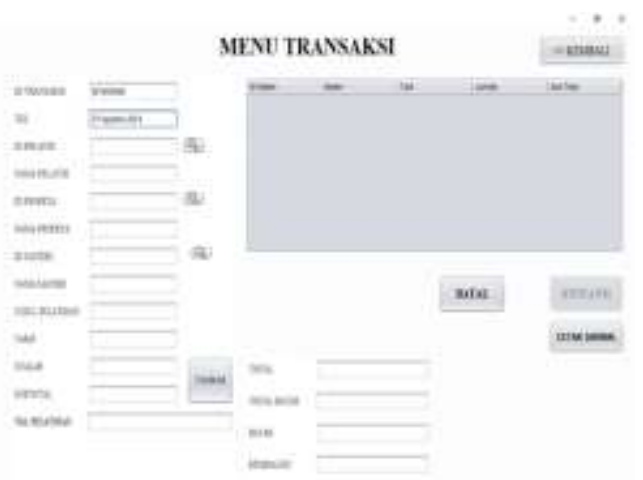

Gambar 10. Tampilan Menu Transaksi
Tampilan Menu Transaksi berikut ini berfungsi mendata Id Pelatih, Nama Pelatih, Id Peserta, Nama Peserta, Id Materi, Nama Materi, Judul Pelatihan, Tarif, Jumlah Harga Pelatihan, Subtotal harga pelatihan, dan Tanggal Pelatihan yang akan di proses oleh karyawan. Setelah itu akan keluar Output Kwintansi dan Output Cetak Jadwal.

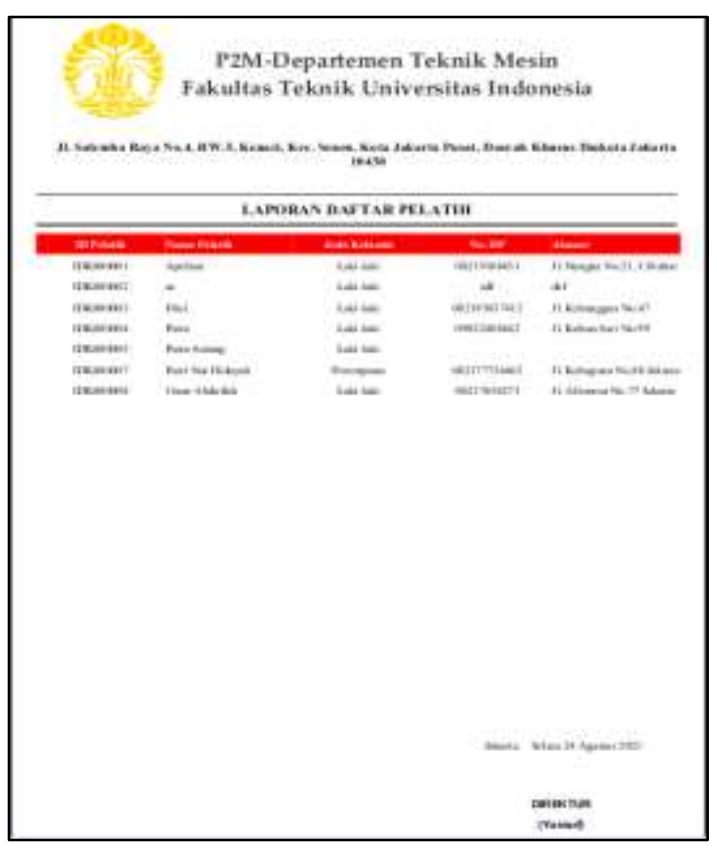

Gambar 11. Tampilan Laporan Data pelatih

Tampilan Menu Laporan Daftar Pelatih berikut ini berfungsi menampilkan Output Daftar Pelatih yang berisi ID Pelatih, Nama Pelatih, Jenis Kelamin, No HP, dan Alamat. Laporan tersebut selanjutkan akan diberikan kepada peserta pelatihan dan Direktur melalui karyawan.

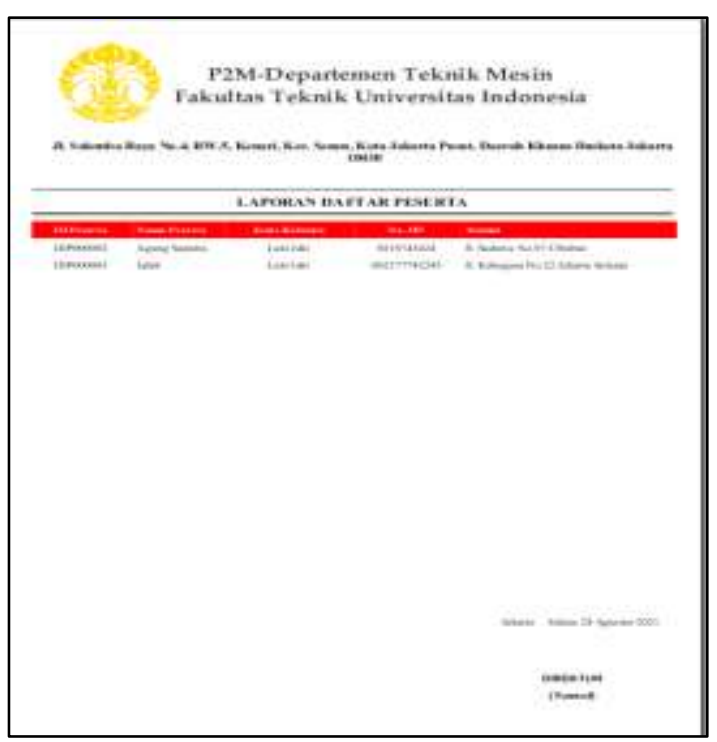

Gambar 12. Tampilan Laporan Data Peserta 
Tampilan Menu Laporan Data Peserta berikut ini berfungsi menampilkan Output Data Peserta yang berisi ID Peserta, Nama Peserta, Jenis Kelamin, No HP, dan Alamat. Laporan tersebut selanjutkan akan diberikan kepada Direktur.

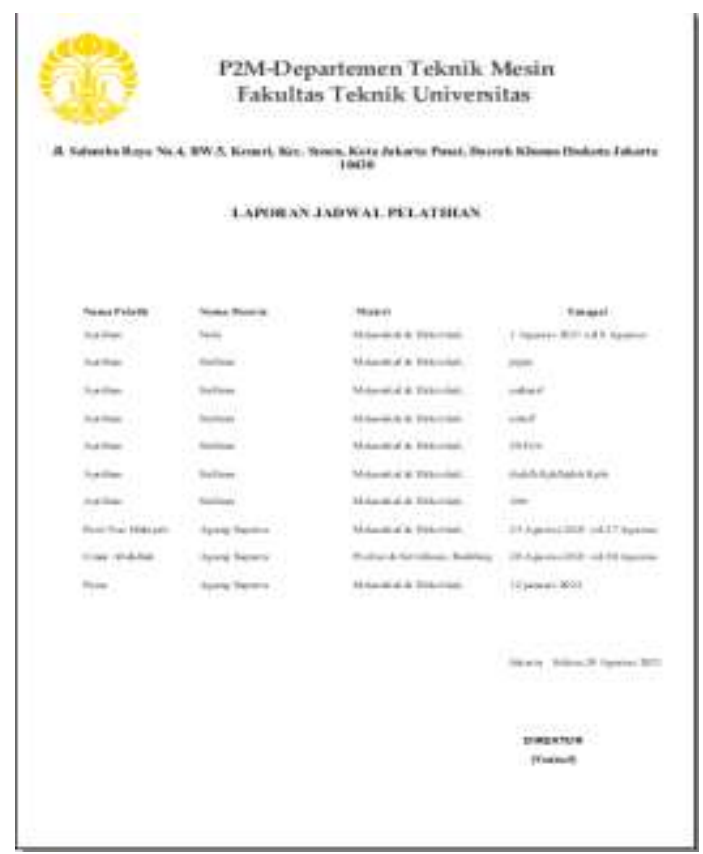

Gambar 13. Tampilan Laporan Jadwal Pelatihan

Tampilan Menu Laporan Jadwal Pelatihan berikut ini berfungsi menampilkan Jadwal Pelatihan yang nantinya akan dilaksanakan. Didalamnya juga terdapat Nama Pelatih, Nama Peserta, Materi, dan Tanggal Pelatihan.

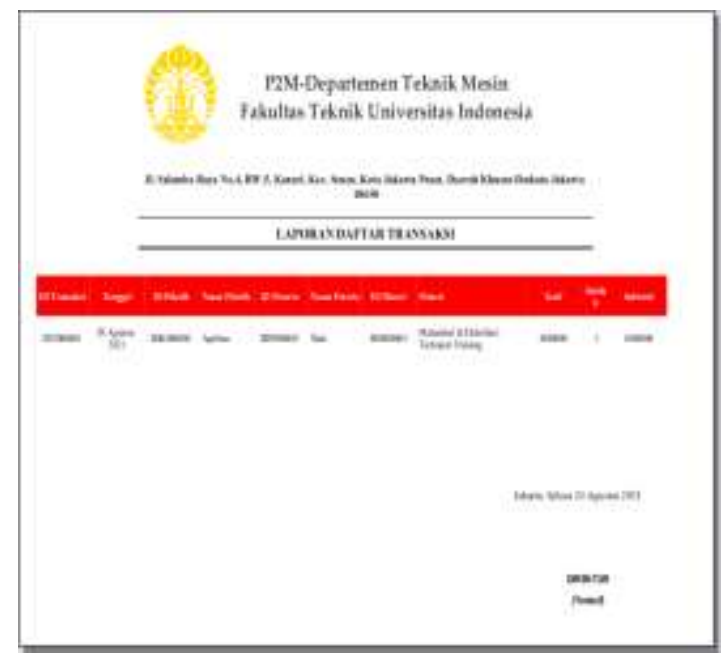

Gambar 14. Tampilan Laporan Transaksi

Tampilan Menu Transaksi berikut ini berfungsi menampilkan Nota Pembayaran yang berisi ID Transaksi, Tanggal, ID Pelatih, Nama Pelatih, ID Peserta, Nama Peserta, ID
Materi, Tarif, Jumlah, dan Subtotal. Nantinya Nota Pembayaran ini akan diberikan kepada peserta dan Direktur melalui karyawan.

\section{SIMPULAN DAN SARAN}

Perancangan sistem informasi pendataan pelatihan P2M Departemen Teknik Mesin Universitas Indonesia meliputi beberapa tahap, yaitu: menyiapkan detail rancangan sistem informasi pendataan pelatihan, mengidentifikasi berbagai alternatif permasalahan, dan melakukan tahap implementasi selain itu, proses pengelolaan data peserta dilakukan secara sistematis mulai dari tahap pendaftaran seperti masukan data peserta yang telah diterima oleh karyawan ketika karyawan sudah memasukan data pendaftaran maka peserta dapat memilih data materi yang disediakan oleh P2M Departemen Teknik Mesin Universitas Indonesia dan data akan tersimpan kedalam database. Lalu tahap selanjutnya peserta dapat melakukan pembayaran kepada karyawan yang akan dimasukan oleh karyawan kedalam data pembayaran setelah itu karyawan akan memberikan nota pembayaran kepada peserta. Tahap ketiga adalah karyawan memasukan data pelatih kedalam database sesuai dengan materi. Tahap terakhir, karyawan memberikan jadwal pelatihan kepada peserta, sampai kepada proses pembuatan laporan yang nantinya dijadikan arsip pada P2M Departemen Teknik Mesin Universitas Indonesia dan laporan kepada Direktur.

Sistem yang sudah dirancang dan dibuat ini telah dilakukan pengujian sehingga dapat digunakan untuk membantu karyawan dalam mengelola data-data yang ada. Hal ini didukung karena sistem yang telah berhasil pengujiannya telah terkomputerisasi sehingga data peserta menjadi lebih efektif dan efisien dan dengan adanya sebuah sistem informasi pendataan pelatihan peserta yang sudah terkomputerisasi dapat mendukung tercapainya proses pengelolaan data peserta dan meminimalisir tingkat kesalah ketika proses pengelolaan sedang berlangsung. Akan tetapi sistem yang sudah terkomputerisasi ini tidak menjamin sepenuhnya selalu sempurna, bisa saja pada saat yang sama sistem mengalami kerusakan atau error ketika sedang digunakan. Maka dari itu diperlukan adanya pemeliharaan dan pemeriksaan secara 
berkala demi menghindari kerusakan sistem yang sudah ada.

Saran yang dapat diberikan oleh peneliti adalah:

Sistem aplikasi yang sudah dibangun bisa dikembangkan kearah jaringan client server sehingga bisa mempercepat proses pengolahan data dan transaksi selain itu, sistem aplikasi hanya mencakup pendataan pelatihan, kedepannya bisa ditambahkan informasi tentang pelatihan pada P2M Departemen Teknik Mesin Universitas Indonesia serta, dikarenakan sistem aplikasi yang dibuat hanya dapat diakses oleh karyawan, kedepannya aplikasi dapat dibuat hak akses yang dapat diakses oleh direktur agar pendataan dapat transparan.

\section{DAFTAR PUSTAKA}

Ahmad. (2018). Analisis Rancangan Sistem Informasi Kepegwaian Dalam Meningkatkan Efisiensi Kerja Pada Kantor Camat Somba Opu Kabupaten Gowa.

Bobby. (2020). Analisis Dan Perancangan Sistem Informasi Pembelian Dan Persediaan Barang Berbasis Web Pada Cv. Panzer Nusa Timur Dengan Metode Economic Order Quantity (Eoq).

Darna, N., \& Herlina, E. (2018). Memilih Metode Penelitian Yang Tepat: Bagi Penelitian Bidang Ilmu Manajemen. 5(April), 287-292.

Medan, P. G., \& Utara, S. (2018). Penerapan Metode Waterfall Dalam Penerapan Aplikasi Mobil Dan Persediaan Barang Pada Bengkel Turbo Otomotif. 3(1), 4045.

Pauziah, U. (2013). Perancangan Sistem Pendataan Penduduk Pada Kelurahan Cililitan Jakarta Timur Berbazis Delphi. Faktor Exacta 6(3): 189-199, 6(3), 189199.

Subhan. (2012). Rancang Bangun Sistem Informasi Penyewaan Lahan Parkir Berbasis Web Gis. Jurnal Sistem Informasi Dan Sains Teknologi, 1(1), 19.

Https://Doi.Org/10.31326/Sistek.V1i1.3 20

Sutabri, T. (2012). Analisis Sisem Informasi.

Tanujaya, C. (2017). Perancangan Standart Operational Procedure Produksi Pada Perusahaan Coffeein. 2(April).
Yulianti, E. (2015). Pengaruh Pelatihan Terhadap Kinerja Karyawan Grand Fatma Hotel Di Tenggarong Kutai Kartanegara. Ejournal Administrasi Bisnis, 2355-5408. 